\title{
Keanekaragaman dan Dominansi Rumput Laut Hidrokoloid pada Substrat yang berbeda di Perairan Pantai Karangtengah Nusakambangan Cilacap
}

\author{
Fakultas Biologi, Universitas Jenderal Soedirman \\ Jalan dr. Suparno 63 Purwokerto 53122 \\ email: bayuardiyanto.95@gmail.com
}

Bayu Ardiyanto; Achmad Ilalqisny Insan; Dwi Sunu Widyartini

Rekam Jejak Artikel:
Diterima : $10 / 07 / 2020$
Disetujui : $19 / 11 / 2020$

\begin{abstract}
The waters of Karangtengah Nusakambangan Cilacap have various types of substrates, namely sand, coral and mixture. Beach conditions with many types of substrates allow various species of seaweed to grow. Information regarding the diversity and dominance of seaweed producing hydrocolloid species has not been much studied in the waters of Karangtengah Beach. This study aims to determine the diversity and dominance of seaweed producing hydrocolloids on different substrates in the waters of Karangtengah Nusakambangan Cilacap. This study uses a survey method with a sampling technique that is the selected random transect method. Six transect lines were made perpendicular to the coastline and the distance between transects was $25 \mathrm{~m}$. Each transect was made three plots, each plot measuring $1 \mathrm{x} 1 \mathrm{~m}$ based on the substrate (coral, sand, and mixture). The main parameters observed were the amount of biomass and the number of species. Supporting parameters observed were environmental factors namely temperature, salinity, $\mathrm{pH}$, current speed and depth. The number of hydrocolloid seaweed species found was 10 species of seaweed with details of 5 alginate-producing species, 3 agarproducing species, and 2 carrageenan-producing species. The diversity index value in the coastal waters of Karangtengah between 0,6-2,0 was classified as moderate diversity. The dominance index value in the coastal waters of Karangtengah between 0,2-0,6 was classified as low dominance.
\end{abstract}

Key words: diversity, dominance, hydrocolloid, seaweed

\section{Abstrak:}

Perairan Pantai Karangtengah Nusakambangan Cilacap memiliki berbagai macam tipe substrat yaitu pasir, karang, dan campuran. Kondisi pantai dengan banyak tipe substrat memungkinkan berbagai spesies rumput laut untuk tumbuh. Informasi terkait keanekaragaman dan dominansi spesies rumput laut penghasil hidrokoloid di perairan Pantai Karangtengah belum banyak diteliti. Penelitian ini bertujuan untuk mengetahui keanekaragaman dan dominansi rumput laut penghasil hidrokoloid pada substrat yang berbeda di perairan Pantai Karangtengah Nusakambangan Cilacap. Penelitian ini menggunakan metode survei dengan teknik pengambilan sampel yaitu metode transek acak terpilih. Sebanyak enam garis transek dibuat secara tegak lurus dengan garis pantai dan jarak antar transek $25 \mathrm{~m}$. Setiap transek dibuat tiga plot yang masing-masing plot berukuran $1 \times 1 \mathrm{~m}$ berdasarkan substratnya (karang, pasir, dan campuran). Parameter utama yang diamati yaitu jumlah biomassa dan jumlah spesies. Parameter pendukung yang diamati adalah faktor lingkungan yaitu temperatur, salinitas, $\mathrm{pH}$, kecepatan arus dan kedalaman. Jumlah spesies rumput laut hidrokoloid yang ditemukan sebanyak 10 spesies rumput laut dengan rincian 5 spesies penghasil alginat, 3 spesies penghasil agar, dan 2 spesies penghasil karaginan. Nilai indeks keanekaragaman di perairan pantai karangtengah antara 0,6-2,0 tergolong keanekaragaman sedang. Nilai indeks dominansi di perairan Pantai Karangtengah antara 0,2-0,6 tergolong dominansi rendah.

Kata kunci: dominansi, hidrokoloid, keanekaragaman, rumput laut

\section{PENDAHULUAN}

Keanekaragaman

adalah sifat yang

memperlihatkan tingkat beragamnya spesies organisme pada suatu komunitas. Namun, pada kondisi tertentu muncul spesies yang dominan dalam komunitas. Dominansi suatu spesies menunjukkan bahwa spesies tersebut dapat 
memanfaatkan sumberdaya dan lingkungan yang ada secara efisien daripada spesies lainnya. Perhatian terhadap sumber daya rumput laut sebagai penghasil hidrokoloid menjadikan studi keanekaragaman dan dominansi spesies rumput laut sangat penting untuk pengelolaan sumber daya rumput laut yang lebih baik. Informasi yang dihasilkan dari studi keanekaragaman dan dominansi spesies rumput laut akan sangat membantu dalam berbagai aspek penelitian lainnya terkait kemudahan dalam pengumpulan spesies rumput laut tertentu di alam (Sahayaraj et al., 2014).

Rumput laut merupakan tumbuhan bertalus yang perawakannya (habitusnya) sulit dibedakan antara akar, batang dan daunnya. Keseluruhan bagian tubuhnya disebut dengan talus. Rumput laut dibedakan dalam tiga divisio utama berdasarkan atas kandungan pigmen yang dominan pada rumput laut tersebut yaitu Rhodophyta (alga merah), Phaeophyta (alga coklat) dan Chlorophyta (alga hijau) (Anggadiredja et al., 2006).

Rumput laut merupakan sumber hayati laut yang jika diproses lebih lanjut, maka menghasilkan senyawa hidrokoloid. Hidrokoloid merupakan produk dari proses metabolisme primer rumput laut. Hidrokoloid adalah suatu polimer larut dalam air yang mampu mengentalkan larutan atau membentuk gel dari larutan tersebut. Ada tiga macam hidrokoloid yang dihasilkan rumput laut yaitu agar, karaginan dan alginat. Tiga hidrokoloid tersebut biasanya dipakai sebagai bahan penyuspensi, pengemulsi, stabilisator, pengikat, pembentuk gel dan lainlainnya. Fungsi tersebut hampir semuanya sangat terkait dalam proses produksi di berbagai industri seperti industri makanan, minuman, farmasi, kosmetik, cat, dan fotografi (Anggadiredja et al., 2006). Banyak fungsi dan manfaat yang dihasilkan oleh kandungan hidrokoloid rumput laut. Masyarakat diharapkan mampu memanfaatkan sumber hayati rumput laut dengan lebih baik

Salah satu aspek yang mempengaruhi keanekaragaman dan dominansi rumput laut alam adalah tipe substrat dasar perairan. Makroalga di alam hidup menempel pada substrat yang stabil untuk menjaga posisinya agar tidak hanyut terbawa oleh arus, gelombang, dan pasang surut (Satheesh \& Wesley, 2012). Ada dua tipe substrat utama yang digunakan sebagai tempat hidup rumput laut yaitu substrat lunak yang meliputi lumpur, pasir atau campuran pasir dan lumpur, dan substrat keras yang meliputi karang mati, karang hidup dan batuan (Ferawati et al., 2014).

Pantai Karangtengah merupakan pantai yang letaknya tidak menghadap langsung ke laut lepas dan lokasinya terlindung oleh cekungan pulau Nusakambangan, sehingga ombak yang dihasilkan tidak terlalu besar. Pantai Karangtengah memiliki beberapa tipe substrat ada yang berupa pasir, karang terjal, dan pecahan karang. Perbedaan kondisi substrat lingkungan mempengaruhi sebaran dan keanekaragaman organisme yang ada di dalamnya, khususnya rumput laut. Kadi (2004) menyatakan bahwa kehadiran rumput laut di perairan Indonesia banyak dijumpai di perairan pantai yang mempunyai paparan terumbu karang.

Pantai Karangtengah merupakan salah satu pantai di wilayah Kabupaten Cilacap yang memiliki potensi keanekaragaman rumput laut penghasil hidrokoloid yang sangat besar. Namun, informasi mengenai keanekaragaman rumput laut yang mempunyai potensi sebagai penghasil hidrokoloid di Pantai Karangtengah, Nusakambangan, Cilacap masih belum banyak diketahui sehingga pemanfaatan sumber hayati rumput laut penghasil hidrokoloid oleh 
BioEksakta: Jurnal Ilmiah Biologi Unsoed

Volume 2, Nomor 3 (2020): 350 - 359

masyarakat sekitar perairan Pantai Karangtengah masih kurang.

\section{MATERI DAN METODE}

Bahan yang digunakan dalam penelitian adalah rumput laut hidrokoloid yang terdapat pada substrat pasir, substrat karang dan substrat campuran di perairan Pantai Karangtengah Nusakambangan Cilacap yang terletak di sekitar

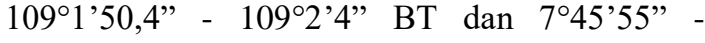

$7^{\circ} 45^{\prime} 57,5^{\prime}$ 'LS (Gambar 1.). Alat yang digunakan yaitu termometer, hand refractometer, botol plastik yang dimodifikasi, kertas $\mathrm{pH}$, dan penggaris. Identifikasi dilaksanakan di Laboratorium Biologi Akuatik Fakultas Biologi Universitas Jenderal Soedirman. Waktu penelitian dilaksanakan pada bulan Januari-Juni tahun 2019.

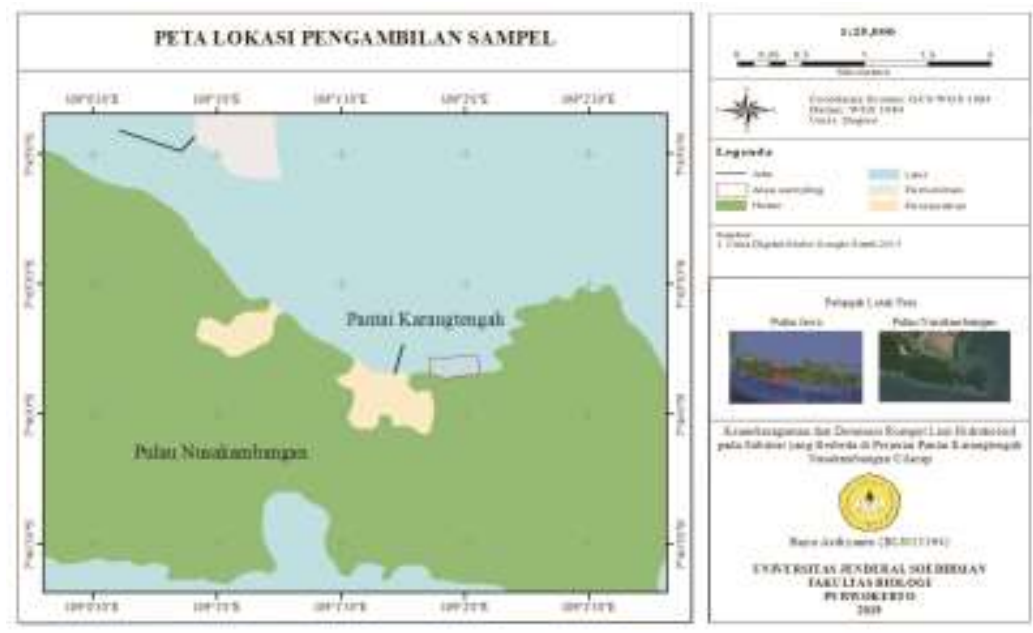

Gambar 1. Peta Lokasi Pengambilan Sampel

Variabel dalam penelitian ini adalah keanekaragaman dan dominansi rumput laut hidrokoloid. Parameter utama yang diamati meliputi jumlah spesies dan jumlah biomassa rumput laut hidrokoloid yang ada di perairan Pantai Karangtengah. Sedangkan parameter pendukungnya adalah faktor lingkungan yaitu nilai temperatur, salinitas, $\mathrm{pH}$, kecepatan arus dan kedalaman.

Metode yang digunakan dalam penelitian ini adalah metode survei dengan teknik pengambilan sampel menggunakan metode transek secara acak terpilih. Sebanyak 6 garis transek dibuat secara tegak lurus dengan garis pantai dan jarak antar transek $25 \mathrm{~m}$. Setiap transek dibuat 3 plot yang masing-masing plot berukuran 1x1 $\mathrm{m}$ berdasarkan substratnya (karang, pasir, dan campuran). Setelah itu, spesies rumput laut ditimbang berat basahnya dan dihitung biomassanya. Rumput laut diidentifikasi dengan menggunakan buku identifikasi Trono (1988); Atmadja et al. (1996); \& Anggadireja et al. (2006).

\section{Keanekaragaman rumput laut}

Keanekaragaman rumput laut secara kuantitatif dihitung menggunakan indeks keanekaragaman Shannon-Wiener (Odum, 1971) dengan rumus :

$$
\mathrm{H}^{\prime}=-\sum_{i=1}^{s}\left(\frac{\mathrm{ni}}{\mathrm{N}} \ln \frac{\mathrm{ni}}{\mathrm{N}}\right)
$$

Keterangan:

$\mathrm{H}^{\prime} \quad$ : Indeks keanekaragaman

ni : Jumlah biomassa tiap spesies

$\mathrm{N} \quad$ : Jumlah total biomasssa

Indeks dominansi Simpson ini bernilai antara 0-1 (Ferawati et al., 2014), yaitu:

$\mathrm{H}^{\prime}<1$ : Menunjukkan bahwa keanekaragaman spesies pada suatu transek adalah rendah.

$1 \leq \mathrm{H}^{\prime} \leq 3 \quad$ : Menunjukkan bahwa keanekaragaman spesies pada suatu transek adalah sedang melimpah.

H'>3 : Menunjukkan bahwa keanekaragaman spesies pada suatu transek 
adalah melimpah tinggi.

\section{Dominansi}

Dominansi pada masing-masing substrat dapat diketahui menggunakan rumus indeks dominansi Simpson (Odum, 1971) yaitu :

$$
\text { Indeks dominansi }(\mathrm{D})=\sum\left(\frac{\text { Jumlah biomassa tiap spesies }(\mathbf{n i})}{\text { Jumlah total biomassa }(\mathbf{N})}\right)^{2}
$$

Indeks domınansı simpson inı bernıla1 antara 0-1 (Ferawati et al., 2014), yaitu:

D: $0<\mathrm{D}<1$, berarti tidak terdapat jenis yang mendominasi jenis lainya atau komunitas berada dalam kondisi stabil.

D: 1, berarti terdapat jenis yang mendominasi jenis lainya atau komunitas berada dalam kondisi labil karena terjadi tekanan ekologis.

Data yang diperoleh dari hasil perhitungan indeks keanekaragaman dan indeks dominansi dianalisis secara deskriptif untuk mengetahui tingkat keanekaragaman dan dominansi rumput laut hidrokolo1d d1 Perairan Panta1 Karangtengah Nusakambangan Cilacap.

\section{HASIL DAN PEMBAHASAN}

Berdasarkan hasil pengamatan, spesies rumput laut yang ditemukan sebanyak 14 spesies di perairan Pantai Karangtengah Nusakambangan Cilacap. Spesies rumput laut yang memiliki potensi hidrokoloid dari 14 spesies tersebut yaitu sebanyak 10 spesies dengan rincian 5 spesies rumput laut penghasil alginat, 3 spesies rumput laut penghasil agar dan 2 spesies rumput laut penghasil karaginan (Tabel 1.).

Tabel 1. Keanekaragaman spesies Rumput Laut hidrokoloid di Perairan Pantai Karangtengah

\begin{tabular}{cllc}
\hline No. & Spesies rumput laut hidrokoloid & Divisio & Potensi Hidrokoloid \\
\hline 1. & Padina australis & Phaeophyta & Alginat \\
2. & Sargassum crassifolium & Phaeophyta & Alginat \\
3. & Sargassum duplicatum & Phaeophyta & Alginat \\
4. & Sargassum plagyphyllum & Phaeophyta & Alginat \\
5. & Sargassum polycystum & Phaeophyta & Alginat \\
6. & Gracilaria foliifera & Rhodophyta & Agar \\
7. & Gracilaria lichenoides & Rhodophyta & Agar \\
8. & Rhodymenia sp. & Rhodophyta & Agar \\
9. & Eucheuma edule & Rhodophyta & Karaginan \\
10. & Eucheuma spinosum & Rhodophyta & Karaginan \\
\hline
\end{tabular}

Rumput laut yang mengandung alginat banyak ditemukan di perairan Pantai Karangtengah. Spesies tersebut antara lain Sargassum polycystum, Sargassum crassifolium, Sargassum duplicatum, Sargassum plagyphyllum, dan Padina australis. Kadi (2004) menyatakan bahwa rumput laut penghasil alginat umumnya mempunyai holdfast yang besar dan kuat sehingga mudah merekat serta tidak mudah hanyut apabila terkena hempasan gelombang. Rumput laut yang mengandung karaginan hanya ditemukan dua spesies yaitu Eucheuma spinosum dan Eucheuma edule. Menurut Kadi (2004), rumput laut penghasil karaginan umumnya mempunyai talus yang kecil dan rapuh sehingga mudah patah apabila terkena hempasan gelombang. Rumput laut yang mengandung agar ditemukan sebanyak tiga spesies yaitu Gracilaria foliifera, Rhodymenia sp., dan Gracilaria lichenoides. Selanjutnya dikatakan pula bahwa rumput laut penghasil agar banyak ditemukan di perairan yang memiliki gelombang kecil. Spesies 
rumput laut yang tidak mengandung hidrokoloid yaitu Acanthopora spicifera, Ulva rigida, Chaetomorpha crassa, dan Valoniopsis pacynema (Atmaja et al., 1996).

Proporsi spesies rumput laut hidrokoloid pada substrat karang, pasir, dan campuran diperairan Pantai Karangtengah (Gambar 2.). Rumput laut penghasil alginat yang ditemukan di perairan Pantai Karangtengah memiliki proporsi $56 \%$ pada substrat karang, 50\% pada substrat pasir dan $25 \%$ pada substrat campuran. Erlania \& Radiarta (2015) menyatakan bahwa rumput laut penghasil alginat dapat ditemukan di daerah dengan substrat dasar yang didominasi oleh pecahan karang. Substrat batu karang dapat dijumpai pada pulau-pulau yang mempunyai arus deras dan ombak besar yang secara tidak langsung berfungsi untuk menahan erosi pantai. Rumput laut penghasil karaginan yang ditemukan di perairan Pantai Karangtengah memiliki proporsi $22 \%$ pada substrat karang dan $25 \%$ pada substrat campuran, namun tidak ditemukan pada substrat pasir.

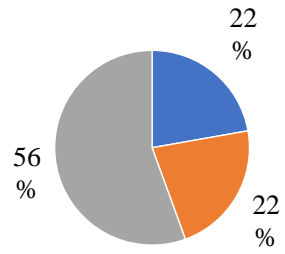

A

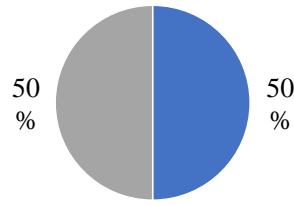

B

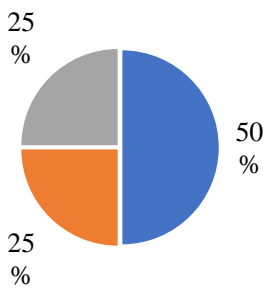

C

Keterangan:

A: Substrat Karang; $\quad$ B: Substrat Pasir; $\quad$ C: Substrat Campuran

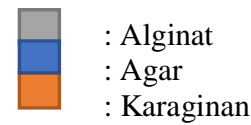

Gambar 2. Proporsi spesies rumput laut hidrokoloid pada substrat karang, pasir dan campuran di perairan Pantaii Karangtengah

Menurut Erlania \& Radiarta (2015), rumput laut penghasil karaginan umumya memiliki talus yang rapuh sehingga tidak dapat tumbuh pada pasir yang membutuhkan talus dan holdfast yang kuat. Rumput laut penghasil agar yang ditemukan di perairan Pantai Karangtengah memiliki proporsi $22 \%$ pada substrat karang, $50 \%$ pada substrat pasir dan $50 \%$ pada substrat campuran. Rumput laut penghasil agar umumnya banyak ditemukan pada pantai yang memiliki gelombang kecil sehingga mampu tumbuh pada berbagai macam substrat. Rumput laut penghasil agar banyak ditemukan pada habitat dasar dengan tipe substrat berupa asosiasi antara pasir, karang hidup, dan batu karang (Erlania \& Radiarta, 2015).

Substrat merupakan faktor penting untuk kelangsungan hidup rumput laut. Jenis substrat pada perairan pantai yang berbeda-beda berpengaruh pada keanekaragaman dan persebaran rumput laut. Substrat karang dapat dijumpai pada pulau-pulau yang mempunyai arus deras dan ombak besar dan berfungsi secara tidak langsung untuk menahan erosi pantai. Rumput laut yang tumbuh dengan cara melekat menggunakan holdfast berbentuk cakram, kebanyakan berada di daerah tubir, dari genus Gelidium, Gelidiopsis, Gelidiella, Hypnea, 
Laurecia, Hormophysa, Turbinaria, dan Sargassum. Pasir merupakan substrat bagi tempat tumbuh hampir semua spesies rumput laut dengan cara holdfast menancap, menempel atau mengikat partikel-partikel pasir. Pengikat substrat ini kebanyakan dimiliki oleh genus Caulerpa, Gracilaria, Eucheuma, dan Acanthophora, tumbuh di seluruh perairan pantai di Indonesia (Johan et al., 2015). Histogram yang menunjukkan tingkat biomassa rumput laut yang mengandung hidrokoloid di perairan Pantai Karangtengah (Gambar 3).

Biomassa terbesar pada substrat karang, pasir, dan campuran adalah spesies Gracilaria lichenoides dengan biomassa yaitu 224 g.m ${ }^{-2}, 38$ g. $\mathrm{m}^{-2}$, dan 90 g. $\mathrm{m}^{-2}$. Ini menunjukkan bahwa Gracilaria lichenoides dapat tumbuh pada berbagai substrat karena memiliki kemampuan adaptasi yang cukup tinggi. Gracilaria lichenoides memiliki holdfast yang kuat untuk membantu melekat pada berbagai tipe substrat sehingga tidak mudah terhempas oleh gelombang dan membentuk rumpun yang rimbun (Indrawati et al., 2010). Biomassa terkecil pada masingmasing substrat yaitu substrat karang adalah Sargassum duplicatum dengan biomassa 18 g.m $\mathrm{m}^{-2}$, substrat pasir yaitu Padina australis dengan biomasaa 12 g.m $\mathrm{m}^{-2}$ dan substrat campuran yaitu Gracilaria foliifera dengan biomassa 19 g.m $\mathrm{m}^{-2}$. Spesies rumput laut Sargassum duplicatum, Padina australis, dan Gracilaria foliifera memiliki jumlah biomassa terkecil pada masingmasing substrat. Hal ini dikarenakan proses pengambilan sampel dilakukan pada musim hujan. Sesuai dengan pernyataan Handayani \& Kadi (2007) yang menyatakan bahwa kesuburan dan biomassa rumput laut di suatu perairan tergantung pada faktor lingkungan seperti keadaan substrat, kondisi perairan dan musim.

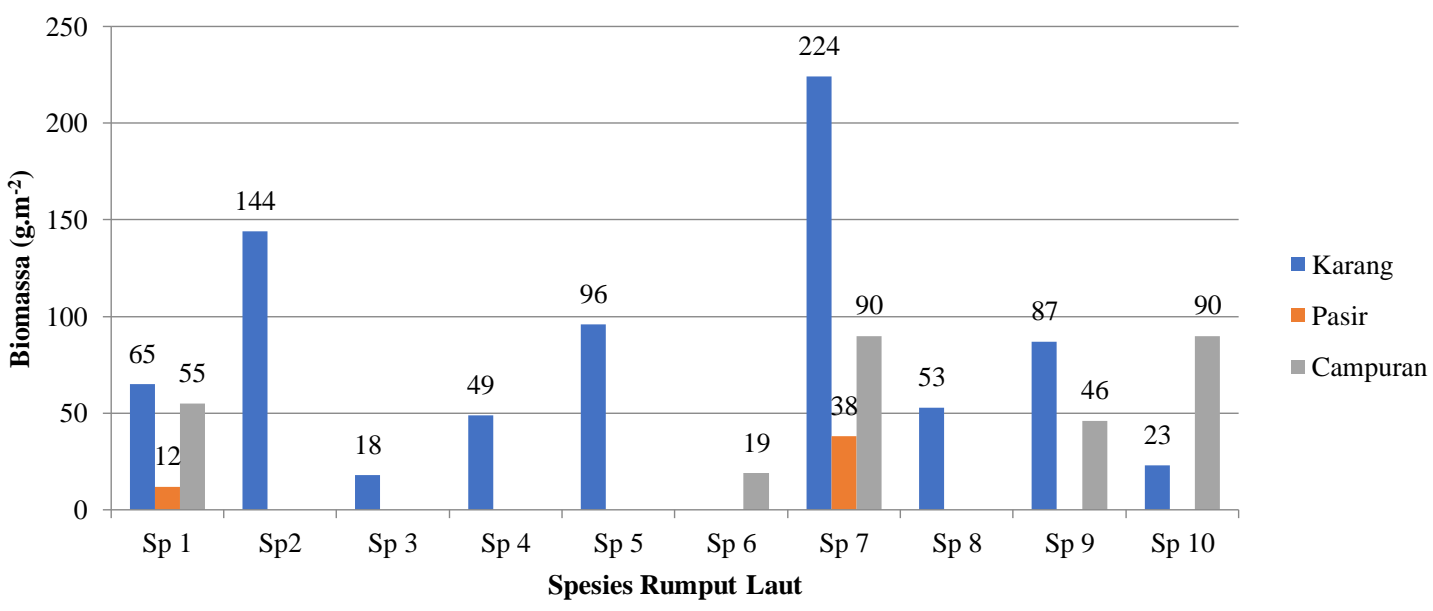

Gambar 3. Histogram biomassa rumput laut hidrokoloid

\section{Keterangan :}

Sp.1 (Padina australis), Sp.2 (Sargassum crassifolium), Sp.3 (Sargassum duplicatum), Sp.4 (Sargassum plagyphyllum), Sp.5 (Sargassum polycystum), Sp.6 (Gracilaria foliifera), Sp.7 (Gracilaria lichenoides), Sp.8 (Rhodymenia sp.), Sp.9 (Eucheuma edule), Sp.10 (Eucheuma spinosum).

Jumlah spesies rumput laut yang tumbuh pada substrat karang lebih banyak dari pada substrat campuran dan substrat pasir. Substrat karang bersifat stabil sehingga rumput laut dapat melekat kuat pada substrat sehingga tidak mudah terhempas pada saat gelombang besar. Catatan hasil penelitian Erlania \& Radiarta (2015) menunjukkan bahwa sebaran habitat rumput laut di Indonesia banyak terdapat pada daerah rataan terumbu karang. Menurut Hartono et al. (2016), 
kondisi substrat yang stabil merupakan tempat yang baik bagi pertumbuhan rumput laut. Substrat campuran terdiri atas karang atau pecahan karang yang tercampur pasir sehingga bersifat tidak stabil sehingga rumput laut mudah terhempas pada saat gelombang besar. Spesies pada substrat pasir tumbuh lebih sedikit dibandingkan dengan spesies pada substrat karang karena pasir merupakan substrat yang mudah terbawa oleh gelombang ataupun arus, selain itu holdfast kurang kuat untuk melekat dan talusnya tidak terlalu kuat. Kadi (2004) menyatakan bahwa substrat pasir mudah sekali terbawa arus air dan menyebabkan distribusi organisme laut menjadi tidak beraturan.

Biomassa rumput laut pada ketiga substrat memiliki nilai yang berbeda, nilai biomassa tertinggi terdapat pada substrat karang. Tingginya biomassa pada substrat karang dapat dipengaruhi oleh faktor lingkungan, adanya proses dominansi dan ciri-ciri spesies rumput laut yang didapat. Handayani \& Kadi (2007) menyatakan bahwa kesuburan dan biomassa rumput laut di suatu perairan tergantung pada faktor lingkungan seperti keadaan substrat, kondisi perairan dan musim. Biomassa rumput laut pada substrat pasir jumlahnya lebih sedikit dibandingkan pada substrat karang dan campuran karena substrat pasir merupakan substrat tidak stabil. Papalia \& Arfah (2013) menyatakan bahwa kemampuan melekat rumput laut pada substrat tergantung pada macam holdfast dan kondisi substrat yang ada. Menurut Kadi (2004), keadaan substrat pasir yang tidak stabil menyebabkan jumlah spesies rumput laut yang tumbuh menjadi sedikit.

Hasil perhitungan indeks keanekaragaman rumput laut hidrokoloid yang didapat di perairan Pantai Karangtengah Nusakambangan Cilacap menunjukkan bahwa ketiga substrat mempunyai komposisi nilai yang berbeda, dengan indeks keanekaragaman berkisar antara 0,6-2,0 yang artinya perairan Pantai Karangtengah memiliki tingkat keanekaragaman rumput laut hidrokoloid yang sedang (Tabel 2.). Jika nilai indeks keanekaragaman (H') kurang dari 1, maka keanekaragaman spesies termasuk sedikit atau rendah. Jika nilai indeks keanekaragaman berada diantara 1 sampai $3 \quad\left(1 \leq \mathrm{H}^{\prime} \leq 3\right)$, maka keanekaragaman spesies pada suatu transek adalah sedang melimpah. Jika nilai indeks keanekaragaman melebihi 3, maka nilai tersebut menunjukkan tingkat keanekaragaman yang melimpah tinggi (Ferawati et al., 2014).

Tabel 2. Nilai Indeks Keanekaragaman Rumput Laut Hidrokoloid

\begin{tabular}{|c|c|c|c|}
\hline No & Substrat & Nilai Indeks Keanekaragaman & Keterangan \\
\hline 1. & Karang & 2,0 & Keanekaragaman sedang \\
\hline 2. & Pasir & 0,6 & Keanekaragaman rendah \\
\hline 3. & Campuran & 1,3 & Keanekaragaman sedang \\
\hline
\end{tabular}

Keanekaragaman pada substrat karang dan campuran di perairan pantai termasuk melimpah sedang. Hal ini sesuai dengan pernyataan Erlania \& Radiarta (2015), kondisi substrat pada suatu perairan pantai mempengaruhi keanekaragaman dan pertumbuhan rumput laut. Perairan Pantai Karangtengah memiliki sebagian besar tipe substrat batu karang. Tingkat keanekaragaman pada substrat pasir yang rendah disebabkan oleh kompleksitas habitat akibat kerusakan substrat atau gelombang tinggi (Ferawati et al., 2014). Faktor lain yang menyebabkan rendahnya keanekaragaman adalah aktivitas manusia yang berlebihan. Poncomulyo et al. (2006) menyatakan bahwa rumput laut rentan terhadap perubahan atau tekanan ekologis yang mempengaruhinya. Keanekaragaman tertinggi terdapat pada substrat karang diikuti substrat campuran dan terendah 
pada substrat pasir.

Hasil perhitungan indeks dominansi rumput laut hidrokoloid di perairan Pantai Karangtengah berkisar antara 0,2-0,6 yang berarti tidak ada spesies yang mendominasi spesies lainnya (Tabel 3.). Nilai indeks dominansi $\mathrm{D}=$ $0<\mathrm{D}<1$, berarti tidak terdapat jenis yang mendominasi jenis lainya atau komunitas berada dalam kondisi stabil. Jika nilai indeks dominansi $\mathrm{D}=1$, maka terdapat jenis yang mendominasi jenis lainya atau komunitas berada dalam kondisi labil karena terjadi tekanan ekologis (Ferawati et al., 2014).

Tabel 3. Nilai Indeks Dominansi Rumput Laut Hidrokoloid

\begin{tabular}{clcl}
\hline No. & Substrat & Nilai Indeks Dominansi & Keterangan \\
\hline 1. & Karang & 0,2 & Dominansi rendah \\
2. & Pasir & 0,6 & Dominansi rendah \\
3. & Campuran & 0,3 & Dominansi rendah \\
\hline
\end{tabular}

Rendahnya nilai indeks dominansi menunjukkan tidak adanya kompetisi atau persaingan antar spesies dalam komunitas. Setiap spesies mampu memanfaatkan sumber daya dan faktor lingkungan secara baik. Suatu komunitas jika terdapat organisme dengan tingkat dominansi yang rendah, maka keanekaragamannya menjadi tinggi. Hal tersebut sesuai dengan pendapat. Ira (2018) menyatakan bahwa ada hubungan antara keanekaragaman dan dominansi jenis, daerah yang mempunyai tingkat dominansi rendah akan mempunyai tingkat keanekaragaman yang tinggi.
McNaughton \& Wolf (1990) menyatakan bahwa perubahan lingkungan mempengaruhi keanekaragaman spesies, sehingga tidak dapat dihindari bahwa spesies tertentu cenderung berada bersama-sama atau beberapa spesies terdapat dalam jumlah sedikit. Keberadaan rumput laut hidrokoloid di perairan Pantai Karangtengah Nusakambangan Cilacap dipengaruhi oleh faktor lingkungan. Data hasil pengukuran faktor lingkungan dapat dilihat pada Tabel 4.

Tabel 4. Data Parameter Lingkungan Perairan Pantai Karangtengah

\begin{tabular}{|c|c|c|c|c|}
\hline \multirow{2}{*}{ No. } & \multirow{2}{*}{ Parameter pendukung } & \multicolumn{3}{|c|}{ Hasil Pengamatan } \\
\hline & & Ulangan 1 & Ulangan 2 & Ulangan 3 \\
\hline 1. & Temperatur & $28^{\circ} \mathrm{C}$ & $29^{\circ} \mathrm{C}$ & $29^{\circ} \mathrm{C}$ \\
\hline 2. & Salinitas & $34 \%$ & $34 \%$ & $34 \%$ \\
\hline 3. & Derajat Keasaman $(\mathrm{pH})$ & 8 & 8 & 8 \\
\hline 4. & Kecepatan Arus & $48,42 \mathrm{~cm} \cdot \operatorname{detik}^{-1}$ & $39,44 \mathrm{~cm} \cdot$ detik $^{-1}$ & $45,66 \mathrm{~cm} \cdot \operatorname{detik}^{-1}$ \\
\hline 5. & Kedalaman & $28 \mathrm{~cm}$ & $18 \mathrm{~cm}$ & $30 \mathrm{~cm}$ \\
\hline
\end{tabular}

Hasil Pengukuran temperatur di perairan Pantai Karangtengah antara $28-29{ }^{\circ} \mathrm{C}$. Temperatur di lokasi penelitian masih dalam kisaran normal yang dapat ditoleransi oleh rumput laut. Menurut Anggadireja et al. (2006), temperatur optimum untuk pertumbuhan rumput laut berkisar antara $27-30^{\circ} \mathrm{C}$. Hasil pengukuran kedalaman di perairan Pantai Karangtengah Nusakambangan Cilacap pada saat surut adalah $18-30 \mathrm{~cm}$. Menurut Farid (2008), rumput laut di Indonesia tumbuh baik pada kedalaman 20-30 cm, karena umumnya penetrasi cahaya matahari masih baik dan mencapai kedalaman tersebut. Kisaran temperatur yang tinggi di pantai masih dapat ditoleransi oleh spesies rumput laut yang tahan terhadap temperatur tinggi, sehingga tidak menyebabkan kematian. Keadaan substrat yang tidak mengalami kekeringan pada saat surut juga turut mempengaruhinya. Hal ini ditunjukkan dengan kedalaman genangan air laut $18-30 \mathrm{~cm}$, yang 
berarti rumput laut masih terendam oleh air laut sehingga tidak terkena sengatan matahari secara langsung yang dapat menyebabkan kematian bagi rumput laut (Riyayi, 2008)

Salinitas air laut mempengaruhi penyebaran, kelimpahan dan pertumbuhan rumput laut di suatu perairan pantai. Hasil pengukuran salinitas air laut di perairan Pantai Karangtengah Nusakambangan Cilacap adalah 34\%o. Kondisi tersebut mendukung pertumbuhan rumput laut. Jaya \& Rasyid (2009) menyatakan bahwa kisaran salinitas optimum untuk pertumbuhan rumput laut antara 33-38\%o. Keasaman atau pH akan mempengaruhi pertumbuhan rumput laut. Menurut Anggadireja et al. (2006), kondisi pH optimum untuk pertumbuhan rumput laut berkisar antara 6,8-8,2. Hasil pengukuran $\mathrm{pH}$ di perairan Pantai Karangtengah Nusakambangan Cilacap adalah 8. Nilai $\mathrm{pH}$ tersebut merupakan kondisi yang cukup ideal untuk pertumbuhan rumput laut.

Menurut Serdiati \& Widiastuti (2010), pergerakan air yang diakibatkan gelombang permukaan sangat membantu dalam distribusi unsur hara dan fisika kimia air lainnya baik secara horisontal maupun vertikal dalam suatu wilayah perairan. Arus yang baik untuk pertumbuhan

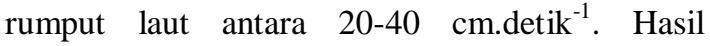
pengukuran kecepatan ombak di perairan Pantai Karangtengah Nusakambangan Cilacap adalah 39,44-48,42 cm.detik $^{-1}$. Berdasarkan kisaran tersebut kecepatan ombak pada lokasi penelitian memenuhi syarat arus yang baik untuk pertumbuhan rumput laut. Perairan Pantai Karangtengah tidak menghadap langsung ke laut lepas dan terlindung oleh cekungan pulau Nusakambangan sehingga ombak yang dihasilkan tidak terlalu besar. Anggadireja et al. (2006) menyatakan bahwa gelombang maupun ombak dengan tekanan yang relatif kuat maka menyebabkan talus rumput laut rusak.

\section{SIMPULAN}

Berdasarkan hasil penelitian dan pembahasan dapat disimpulkan bahwa keanekaragaman rumput laut di perairan Pantai Karangtengah diperoleh 10 spesies penghasil hidrokoloid dengan nilai indeks keanekaragaman 2,0 pada substrat karang (9 spesies rumput laut hidrokoloid), 0,6 pada substrat pasir (2 spesies rumput laut hidrokoloid), dan 1,3 pada substrat campuran (4 spesies penghasil hidrokoloid). Dominansi rumput laut di perairan Pantai Karangtengah tergolong rendah dengan nilai indeks dominansi 0,2 pada substrat karang, 0,6 pada substrat pasir, dan 0,3 pada substrat campuran. Perairan Pantai Karangtengah merupakan pantai dengan keanekaragaman yang cukup melimpah dengan karakteristik substrat pantai yang sebagian besar adalah karang dan gelombang ombak yang tidak terlalu besar, maka perlu adanya upaya pemanfaatan rumput laut hidrokoloid yang hidup pada substrat karang dengan cara budidaya yang ramah lingkungan

\section{DAFTAR REFERENSI}

Anggadiredja, J.T., Zantika, H., Istini, S., \& Purwanto, 2006. Rumput Laut. Jakarta : Penebar Swadaya.

Aslan, L.M., 1991. Budidaya Rumput Laut. Yogyakarta: Kanisius.

Atmadja, W.S., Kadi, A., \& Rachmaniar, 1996. Pengenalan Jenis-Jenis Rumput Laut Indonesia. Jakarta: Puslitbang Oseanografi Lembaga Ilmu Pengetahuan Indonesia.

Connel, Y.H., 1974. Field Experiment in Marine Ecology. New York: Academy Press.

Domettila, C., Brintha, T.S.S., Sukumaran, S., \& Jeeva, S., 2013. Diversity and Distribution of Seaweeds in the Muttom Coastal Waters, South-west Coast of India. Biodiversity Journal, 4(1) : 105110 .

Erlania \& Radiarta, I. N., 2015. Distribusi Rumput Laut Alam Berdasarkan Karakteristik Dasar Perairan di Kawasan Rataan Terumbu Labuhanbua Nusa 
Tenggara Barat : Strategi Pengelolaan untuk Pengembangan Budidaya. Jurnal Riset Akuakultur, 10(3) : 449-457.

Farid, A., 2008. Studi Lingkungan Untuk Budidaya Rumput Laut (Eucheuma cottonii) di Perairan Branta, Pamekasan, Madura. Jurnal Penelitian Perikanan, 11(1) : 1-6.

Ferawati, E., Widyartini, D.S., \& Insan, A.I., 2014. Komunitas Rumput Laut pada Berbagai Substrat di Perairan Pantai Permisan Kabupaten Cilacap. Scripta Biologica, 1(1) : 55-60.

Handayani, T. \& Kadi, A., 2007. Keanekaragaman dan Biomassa Algae di Perairan Minahasa Utara, Sulawesi Utara. Jurnal Oseanologi dan Limnologi di Indonesia, 33(2) : 199-211.

Hartono, Yaqin, K., \& Sitepu, F.G., 2016. Keragaman Jenis Rumput laut di Perairan Littoral Dusun Tamalabba Desa Punaga Kecamatan Mangarabombang Kabupaten Takalar. Jurnal Rumput Laut Indonesia, 1(2) : 77-81.

Indrawati, G., Arthana, I.W., \& Merit, I.N., 2010. Studi Komunitas Rumput Laut di Pantai Sanur dan Pantai Sawangan Nusa Dua Bali. Ecotrophic, 4(2): 73-79.

Insan, A.I. \& Widyartini, D.S., 2001. Makroalga. Purwokerto: Fakultas Biologi Universitas Jenderal Soedirman

Ira, 2018. Struktur Komunitas Makro Alga di Perairan Desa Mata Sulawesi Tenggara. Jurnal Biologi Tropis, 18(1) : 45-56.

Jaya, I., \& Rasyid, A.J., 2009. Kajian Oseanografi untuk Kelayakan Budidaya Beberapa Spesies Rumput Laut di Perairan Pantai Barat Sulawesi Selatan. Torani, 19(3) : 129-136.

Johan, O., Erlania, \& Radiarta, I.N., 2015. Hubungan Substrat Dasar Perairan dengan Kehadiran Rumput Laut Alam di Perairan Ujung Genteng Sukabumi Jawa Barat. Jurnal Riset Akuakultur, 10(4) : 609-618.

Kadi, A., 2004. Potensi Rumput Laut di beberapa Perairan Pantai Indonesia. Oseana, 29(4) :25-36.
Luning, K., 1990. Seaweeds: Their Environment, Biogeography and Ecophysiology. New York : John Wiley \& Sons.

McNaughton, J. \& Wolf, L.L., 1990. Ekologi Umum. Yogyakarta: Gajah Mada University Press.

Odum, E. P., 1971. Fundamental of Ecology. 3rd ed. London: Toppan Company, Ltd.

Papalia, S. \& Arfah, H., 2013. Produktivitas Biomassa Makroalga di Perairan Pulau Ambalau, Kabupaten Buru Selatan, Jurnal Ilmu dan Teknologi Kelautan Tropis, 5(2) : 465-477.

Poncomulyo, T., Herti, M., \& Lusi, K., 2006. Budidaya dan Pengolahan Rumput Laut. Jakarta Agromedia.

Riyayi, P.D., 2008. Keanekaragaman dan Biomassa Rumput Laut Hidrokoloid yang Terdapat di Pantai Rancababakan Cilacap. Skripsi. Purwokerto: Universitas Jenderal Soedirman.

Sahayaraj, K., Rajesh, A., Asha, A., Rathi, J.M., \& Raja, P., 2014. Distribution and Diversity Assessment of The Marine Macroalgae at Four Southern Districts of Tamil Nadu, India. Indian Journal of Geo-Marine Sciences, 43(4) : 607-617.

Satheesh, S. \& Wesley, S.G., 2012. Diversity and Distribution of Seaweeds in the Kudankulam Coastal waters, SouthEastern Coast of India. Biodiversity Journal, 3(1) : 79-84.

Serdiati, N. \& Widiastuti, I. M., 2010. Pertumbuhan dan Produksi Rumput Laut Eucheuma cottonii pada Kedalaman Penanaman yang Berbeda. Media Litbang Sulteng, 3 (1) : 21-26.

Sohrab, D.A., Garavand, K.M., Riahi, H. \& Pashazanoosi, H., 2012. Seasonal Variations in Biomass and Species Composition of Seaweeds along the Northen Coasts of Persian Gulf (Bushehr Province). J. Earth Syst. Sci., 1(1) : 241250.

Trono, G.C.J., \& Fortez, E.T.G., 1988. Philippine Seaweeds. Manila: National Book Store Inc. 